\title{
Upregulation of AKAP12 with HDAC3 depletion suppresses the progression and migration of colorectal cancer
}

\author{
PING HE ${ }^{1-3^{*}}, \mathrm{KE} \mathrm{LI}^{1,2^{*}}$, SHI-BAO LI ${ }^{4}$, TING-TING HU ${ }^{5}$, MING GUAN $^{5}$, FEN-YONG SUN ${ }^{2}$ and WEI-WEI LIU ${ }^{1,2,6}$ \\ ${ }^{1}$ Central Laboratory, and ${ }^{2}$ Department of Laboratory Medicine, Shanghai Tenth People's Hospital, Tongji University, \\ Shanghai 200070; ${ }^{3}$ Department of Nuclear Medicine, Nanjing Hospital, Affiliated to Nanjing Medical University, \\ Nanjing, Jiangsu 210006; ${ }^{4}$ Department of Laboratory Medicine, The Affiliated Hospital of Xuzhou Medical College, \\ Xuzhou, Jiangsu 221100; ${ }^{5}$ Department of Laboratory Medicine, Huashan Hospital, Shanghai Medical College, \\ Fudan University, Shanghai 200040; ${ }^{6}$ Department of Laboratory Medicine, \\ Shanghai Skin Disease Hospital, Tongji University, Shanghai 200071, P.R. China
}

Received July 18, 2017; Accepted February 16, 2018

DOI: $10.3892 /$ ijo.2018.4284

\begin{abstract}
A-kinase anchor protein 12 (AKAP12; also known as Gravin) functions as a tumor suppressor in several human primary cancers. However, the potential correlation between histone deacetylase 3 (HDAC3) and AKAP12 and the underlying mechanisms remain unclear. Thus, in this study, in an aim to shed light into this matter, the expression levels of HDAC3 and AKAP12 in 96 colorectal cancer (CRC) and adjacent noncancerous tissues, as well as in SW480 cells were examined by immunohistochemical, RT-qPCR and western blot analyses. The effects of HDAC 3 and AKAP12 on the proliferation, apoptosis and metastasis of CRC cells were examined by cell counting kit-8 (CCK-8) assay, colony formation assays, flow cytometry, cell cycle analysis and Transwell assays. The results revealed that the reduction or loss of AKAP12 expression was detected in $69(71.8 \%)$ of the 96 tissue specimens, whereas HDAC3 was upregulated in $50(52.1 \%)$ of the 96 tumor tissue specimens. AKAP12 expression was markedly increased upon treatment with the HDAC3 inhibitors, trichostatin A (TSA) and RGFP966, at both the mRNA and protein level. Mechanistically, the direct binding of HDAC3 within the intron-1 region of AKAP12 was identified to be indispensable
\end{abstract}

Correspondence to: Professor Wei-Wei Liu, Central Laboratory and Department of Laboratory Medicine, Shanghai Tenth People's Hospital, Tongji University, 301 Yanchang Road, Shanghai 200072, P.R. China

E-mail: huashanvivian@126.com

Professor Fen-Yong Sun, Department of Laboratory Medicine, Shanghai Tenth People's Hospital, Tongji University, 301 Yanchang Road, Shanghai 200072, P.R. China

E-mail: sunfenyong@263.net

*Contributed equally

Key words: histone deacetylase 3, A-kinase anchor protein 12, colorectal cancer, AKT for the inhibition of AKAP12 expression. Moreover, the proliferation, colony-forming ability, cell cycle progression and the migration of the CRC cells were found to be promoted in response to AKAP12 silencing or AKAP12/HDAC3 co-silencing, whereas transfection with si-HDAC3 yielded opposite effects. Apart from the elevated expression of the anti-apoptotic protein, Bcl-2, after AKAP12 knockdown, the increased activity of PI3K/AKT signaling was found to be indispensable for AKAP12-mediated colony formation and migration. On the whole, these findings indicate that AKAP12 may be a potential prognostic predictor and therapeutic target for the treatment of CRC in combination with HDAC3.

\section{Introduction}

Colorectal cancer (CRC) is the third most common type of cancer and the leading cause of cancer mortality worldwide, accounting for an estimated 10 million new cases and 5 million deaths $(1,2)$. Therefore, a better understanding of the molecular mechanisms underlying the onset and progression of CRC is essential in order to improve the diagnosis, develop new therapies, and achieve an accurate prognosis. Hence, in order to decrease the incidence of late prognosis and prevent subsequent mortality, the identification of additional biomarkers for CRC is paramount.

AKAP12/Gravin (A-kinase anchor protein 12), which was first isolated from the serum of patients with myasthenia gravis (3), is a member of the cyclic AMP-dependent kinaseanchoring protein (AKAP) family and acts as a scaffold protein that assembles multiple signaling molecules at their functional subcellular locations, including protein kinase A, protein kinase $\mathrm{C}$, cyclin D and calmodulin (4,5). Moreover, AKAP12 suppresses Src-induced oncogenic proliferation, invasiveness and cell death by directly scaffolding Src from growth factor receptor and FAK complexes to lipid rafts, without altering the intrinsic kinase activity of Src. In addition, the rodent homologue of AKAP12 impacts the blood-brain barrier via the regulation of vascular endothelial growth factor of astrocytes (6). AKAP12 is located at 6q24-25.2, a depletion 
hotspot that is commonly expressed in tumors of the prostate, breast and ovary. However, accumulating evidence indicates that AKAP12 mRNA is underexpressed or lost in the majority of CRC tissues (7). Moreover, DNA hypermethylation of the AKAP12 promoter region causing the subsequent downregulation of mRNA expression occurs in the majority of human cancers (8-11). Hence, the underexpression or loss of AKAP12 suggests that it may be a potential indicator associated with oncogenesis.

$\mathrm{CRC}$ progression is characterized by epigenetic alterations, including promoter DNA hypermethylation and post-translational modifications of histones. Histone deacetylases (HDACs) are transcriptional co-repressors that remove acetyl groups from histones (12). Previous studies have suggested that the deregulation of HDACs suppresses transcription by tightening the chromatin structure, which further contributes to tumorigenesis. There are three classes of HDACs: Class I, which includes HDAC1, 2, 3 and 8; class II, composed of HDAC4-6, 9 and 10; class III, which includes members of the SIR2 family; and class IV, which has only one member, HDAC11 (12). HDACs catalyze the removal of an acetyl group from the $\varepsilon$-amino group of lysine side chains of the histone molecules H2A, H2B, H3 and $\mathrm{H} 4$, thereby reconstituting a positive charge to the lysine moiety (13). Emerging data suggest that the increased expression of HDACs occurs in several types of cancer other than CRC (14), including cancers of the stomach (15), liver (16), breast (17) and prostate (18), as well as in hematological malignancies (19).

HDAC 3 , in addition to HDAC1, 2 and 8, is a class I HDAC that is expressed extensively in the majority of cancers (20-22). Functionally, HDAC3 has the ability to induce proliferation by activating vitamin $\mathrm{D}$ signaling, reduce apoptotic death, and promote invasion and metastasis by interacting with WD Repeat Domain 5 (WDR5) in a broad spectrum of cancer cells. Furthermore, HDAC3 is considered to play a critical role in the suppression of gene transcription by unliganded or antagonist-bound nuclear hormone receptors, and reportedly forms multi-protein complexes with SMRT and N-CoR (23). Biologically, HDAC3 has been noted for its ability to induce growth, promote metastasis and reduce the apoptotic death of CRC cells by suppressing p21 expression. Mechanically, HDAC3 also influences the phosphorylation of signal transducer and activator of transcription 3 (STAT3) at serine 727 by interacting with protein phosphatase 2 (PP2, also known as PP2A) (24) and regulating the deacetylation of histone and non-histone target proteins (25). Despite there being significant evidence that HDAC3 plays an important role in cancer initialization and progression, there is limited information on the association between HDAC3 and the tumor suppressor factor, AKAP12, in CRC.

The aim of this study was to determine whether HDAC3 and AKAP12 expression play a role in the regulation of CRC progression and metastasis. The results of this study demonstrated that HDAC3 expression was significantly upregulated in CRC cells and tissues, whereas that of AKAP12 was decreased. Importantly, the co-silencing of HDAC3 and AKAP12 inhibited the growth, enhanced the apoptosis and suppressed the migration of CRC cells to a greater extent than the silencing of each factor alone. These findings may prove to be helpful for the further understanding of the unique roles of
HDAC3 and AKAP12 interactions in the onset and progression of CRC.

\section{Materials and methods}

Patients and samples. All specimens were collected from patients with CRC at Huashan Hospital and Shanghai Tenth People's Hospital (Shanghai, China). Written consent was obtained from all subjects and the study protocol was approved by the Ethics Committees of Huashan Hospital and Shanghai Tenth People's Hospital. In total, 96 paired non-tumor adjacent normal tissues and tumor tissues were collected from 96 patients with CRC following surgical resection. All samples were stored in an ultra-low temperature refrigerator.

Cell culture and primary CRC cell isolation. Three CRC cell lines (LoVo, SW480 and LS174T) were obtained from the American Type Culture Collection (ATCC, Manassas, VA, USA). The LoVo cells were cultured in F-12K medium (Gibco/Invitrogen Corp., Grand Island, NY, USA) supplemented with $10 \%$ fetal bovine serum (FBS; Gemini Bio Products, Broderick, CA, USA) and incubated under an atmosphere of $5 \% \mathrm{CO}_{2}$ at $37^{\circ} \mathrm{C}$. The SW480 cells were cultured in L-15 medium containing $10 \%$ FBS without $5 \% \mathrm{CO}_{2}$ and the LS174T cells were maintained in Dulbecco's modified Eagle's medium (DMEM) (both from Gibco) containing 10\% FBS at $37^{\circ} \mathrm{C}$ in a humidified incubator containing $5 \% \mathrm{CO}_{2}$. Approximately $1 \times 10^{6}$ cells were seeded per square in 6-well plates. Following $24 \mathrm{~h}$ of incubation, fresh culture medium with or without Trichostatin A (TSA; $5 \mu \mathrm{mol} / 1$, V900931; Sigma-Aldrich Corp., St. Louis, MO, USA) and RGFP966 (10 $\mu \mathrm{M}$, S7229; Selleckchem, Houston, TX, USA) were added and the cells were further incubated for an additional $48 \mathrm{~h}$. Two inhibitors specifically targeting AKT, MK2206 (2 $\mu \mathrm{M}, \mathrm{S} 1078)$ and AZD5363 (10 $\mu \mathrm{M}, \mathrm{S} 8019)$ (both from Selleckchem), were applied in the presence of si-HDAC3, si-AKAP12 or si-HDAC3 plus si-AKAP12 in the SW480 cells for $6 \mathrm{~h}$. The pmyr-AKT vector was kindly provided by Professor Lei Chen from Eastern Hepatobiliary Surgery Hospital. The exogenous expression of AKT was performed by transient transfection with pmyr-AKT plasmid (1 $\mu \mathrm{g}$ for each well of 6-well plate). Cisplatin was obtained from Selleckchem (S1166). After $48 \mathrm{~h}$ of transfection, the cells were treated with cisplatin $(10 \mu \mathrm{g} / \mathrm{ml})$ for an additional $16 \mathrm{~h}$.

Two human CRC tissues were collected immediately following resection and placed into a sterile tube contain DMEM supplemented with $10 \%$ FBS and $1 \%$ penicillin/streptomycin. The tissues were cut in $1 \mathrm{ml}$ of DMEM plus FBS and antibiotic (penicillin/streptomycin; Invitrogen Corp.). The tissues were then transferred into a $15-\mathrm{ml}$ falcon tube containing $2 \mathrm{ml}$ of medium supplemented with $1,000 \mathrm{U} / \mathrm{ml}$ collagenase II incubated for $10 \mathrm{~min}\left(37^{\circ} \mathrm{C}\right)$, and mixed on a vortex for $10 \mathrm{sec}$. Subsequently, $2 \mathrm{ml}$ of medium/well was removed and added to an equal volume of FBS. This procedure was repeated 3 times. The dissociated cells were harvested by centrifugation $(250 \mathrm{x} \mathrm{g})$ for $10 \mathrm{~min}$, resuspended in DMEM supplement with $20 \%$ FBS and $1 \%$ penicillin/streptomycin, and plated in a 6-well plate. After $24 \mathrm{~h}$, primary CRC cells were transiently transfected with siRNAs, and western blot analysis was performed $48 \mathrm{~h}$ after siRNA transfection. 
Reverse transcription-quantitative PCR (RT-qPCR). Total RNA $(1 \mu \mathrm{g})$ was extracted using TRIzol reagent (Invitrogen Corp.) and reverse transcribed into cDNA using the PrimeScript ${ }^{\mathrm{TM}}$ reagent kit (Takara Bio, Inc., Shiga, Japan). The synthesized cDNA was amplified using the KAPA ${ }^{\mathrm{TM}}$ SYBR $^{\circledR}$ Fast qPCR kit (Kapa Biosystems, Inc., Wilmington, MA, USA) and the Applied Biosystems 7500 Fast Real-Time PCR system (Applied Biosystems, Carlsbad, CA, USA) according to the following protocol: Initial denaturation at $95^{\circ} \mathrm{C}$ for $3 \mathrm{~min}$, then 45 cycles at $95^{\circ} \mathrm{C}$ for $10 \mathrm{sec}, 60^{\circ} \mathrm{C}$ for $34 \mathrm{sec}$, and a final extension at $72^{\circ} \mathrm{C}$ for $5 \mathrm{~min}$. With the reference gene, glyceraldehyde 3-phosphate dehydrogenase (GAPDH), as an internal control, the following forward and reverse primer sequences, respectively, were used for RT-qPCR: HDAC3, 5'-GGA GCT GGA CAC CCT ATG AA-3' and 5'-TAT TGG TGG GGC TGA CTC TC-3'; AKAP12, 5'-GTC TCC TTC ATT CGC AGG CT-3' and 5'-CAT GGC TCC TCC GCA CTT CTC-3'; GAPDH, 5'-GAA GGT GAA GGT CGG AGT CA-3' and 5'-GAA GAT GGT GAT GGG ATT TC-3'; matrix metallopeptidase (MMP)2, 5'-TAC AGG ATC ATT GGC TAC ACA CC-3' and 5'-GGT CAC ATC GCT CCA GAC T-3'; MMP7, 5'-GAG TGA GCT ACA GTG GGA ACA-3' and 5'-CTA TGA CGC GGG AGT TTA ACA T-3'; TIMP2, 5'-AAG CGG TCA GTG AGA AGG AAG-3' and 5'-GGG GCC GTG TAG ATA AAC TCT AT-3'. All primers were synthesized by Sangon Biotech Co. Ltd. (Shanghai, China). Each reaction was performed in triplicate and the $2^{-\Delta \Delta \mathrm{Cq}}$ method was used to calculate relative mRNA abundance $(26,27)$. A positive or negative change in expression of 2-fold or greater was considered significant.

Chromatin immunoprecipitation (ChIP) assay. Chromatin immunoprecipitation was carried out as previously described (28). Briefly, the SW480 cells were fixed in 1\% formaldehyde and protease inhibitor cocktail 1 (PIC1, comprised of $1 \mu \mathrm{g} / \mathrm{ml}$ leupeptin, $1.4 \mu \mathrm{g} / \mathrm{ml}$ pepstatin, $0.2 \mathrm{mg} / \mathrm{ml} \mathrm{PMSF}, 1 \mathrm{mM}$ EGTA and $1 \mathrm{mM}$ EDTA) for $10 \mathrm{~min}$ with gentle rotation at room temperature for $10 \mathrm{~min}$ at room temperature. The crosslinking reaction was quenched with Glycine Stop-Fix solution (Shandong New Beiyang Information Technology Co., Ltd., Beijing, China). The pellet was resuspended in ice-cold lysis buffer and dounced on ice with 10 to 15 strokes to aid nuclei release. Nuclei were released after 30 strokes using a dounce homogenizer and collected following centrifugation $(2,1382 \mathrm{x} \mathrm{g}$, $\left.4^{\circ} \mathrm{C}, 15 \mathrm{~min}\right)$. The pellets were resuspended in $6 \mathrm{ml}$ homogenization buffer (10 mM HEPES, pH 7.6, $25 \mathrm{mM} \mathrm{KCl,} 1 \mathrm{mM}$ EDTA, $1 \mathrm{mM}$ EGTA, $1 \mathrm{M}$ sucrose, $10 \%$ glycerol, $0.15 \mathrm{mM}$ spermine, supplemented with PIC1) and layered onto $3 \mathrm{ml}$ of the same buffer. The nuclei were then pelleted at 5,031 x $\mathrm{g}$ for $1 \mathrm{~h}$ (SW41 rotor; Beckman Coulter, Irving, TX, USA) and stored at $-80^{\circ} \mathrm{C}$. The nuclear pellets were re-suspended in $0.3 \mathrm{ml}$ nuclear lysis buffer (50 mM Tris pH 7.6, $10 \mathrm{mM}$ EDTA and $1 \% \mathrm{SDS}$ ), and diluted with $0.6 \mathrm{ml}$ immunoprecipitation (IP) dilution buffer $(0.01 \%$ SDS, $1.1 \%$ Triton $X-100,167 \mathrm{mM} \mathrm{NaCl}$, $16.7 \mathrm{mM}$ Tris $\mathrm{pH} 7.6,1.2 \mathrm{mM}$ EDTA). For sonication, $0.3 \mathrm{ml}$ $(1 / 3)$ of nuclear lysate was sonicated for 25-30 cycles $30 \mathrm{sec}$ on $30 \mathrm{sec}$ at $4^{\circ} \mathrm{C}$ with a BioRuptor twin sonicator (Diagenode). Sonicated chromatin was then further diluted to $1 \mathrm{ml}$ with IP dilution buffer, which is sufficient for $3 \mathrm{ChIP}$ reactions. The average size of the fragments was $\sim 120-150 \mathrm{bp}$. The SW480 cell chromatin fragments were immunoprecipitated with
anti-HDAC3 antibody (dilution, 1:2,000; ab96005; Abcam, Cambridge, UK). Primer pairs for HDAC3 binding sites in AKAP12 intron-1 regions (pair-2) and for the right (pair-3) or left (pair-1) adjacent to HDAC3 binding sites were used to investigate the binding of HDAC3. The primer pairs are shown as follows: Pair-1 forward, 5'-GTCGCCCTGTTAGAAAC GGG-3' and reverse, 5'-GCACAGCCCCAGACACGCCC-3' (PCR product, 134 bp); Pair-2 forward, 5'-AGATGCTGCTG CAGGGCGTG-3' and reverse, 5'-ACGCGCTCGCGGCAAAC TCC-3' (PCR product, 137 bp); Pair-3 forward, 5'-CGGAGGC TAAGAGGTGGCC-3' and reverse, 5'-CCCGCGAGGTCC CGAGAGCGCC-3' (PCR product, 138 bp).

Luciferase assay. Generally, the SW480 cells were transfected with a firefly luciferase reporter gene construct (pGL3-CMV; E1751; Promega, Madison, WI, USA). Cell extracts were prepared $48 \mathrm{~h}$ following transfection with the luciferase vector, and the relative luciferase activity was measured using the Dual Luciferase Reporter Assay System (E1910; Promega), and was normalized to Renilla luciferase activity. The intron-1 region of AKAP12 was firstly amplified with the following primers: Forward, 5'-GTCGGCTGCAGCAGAAGCTC-3' and reverse, 5'-CCCGCGAGGTCCCGAGAGCGCC-3' and then inserted into the upstream of CMV sequence of pGL3-CMV (E1751; Promega) construct (named as pGL3-CMV-AKAP-Intron-1). In addition, the $\mathrm{E}$ and GC Box deleted intron-1 construct were named as pGL3-CMV-AKAP-Intron-Mutant. The relative luciferase activity was measured as described above. In addition, the above-mentioned experiments were performed at least 3 times before drawing any conclusions.

Transient transfection with siRNA. All siRNAs (S1, S2, S3 and a negative control) used to silence HDACs and AKAP12 were synthesized by Shanghai GenePharma Co., Ltd. (Shanghai, China). siRNA targeting the human Bcl-2 gene (S1915) was purchased from Thermo Fisher Scientific Inc., Waltham, MA, USA). The cells were grown to confluency, trypsinized and resuspended in Opti-MEM ${ }^{\mathrm{TM}}$ I Reduced Serum Media (Gibco). Non-targeting control, HDACs, or AKAP12 siRNA were transfected into the cells using Lipofectamine 2000 reagent (Invitrogen-Life Technologies) with Opti-MEM at a concentration of $100 \mathrm{nM}$. Following transfection for $24 \mathrm{~h}$, RNA was isolated and quantified by RT-qPCR.

Western blot analysis. Total protein was extracted from the CRC cell lines using Cell Lysis Buffer for Western and Immunoprecipitation (Beyotime Institute of Biotechnology, Haimen, China) and the protein concentration was measured using a BCA Protein Reagent kit (Beyotime Institute of Biotechnology). Subsequently, 30-50 $\mu \mathrm{g}$ of protein from each sample were separated by sodium dodecyl sulfate polyacrylamide gel electrophoresis on 10 and $6 \%$ gels, respectively, and transferred onto a polyvinylidene fluoride membrane (EMD Millipore, Temecula, CA, USA). The membrane was then incubated with the following antibodies: HDAC3 (dilution, 1:2,000; ab96005), AKAP12 (dilution, 1:5,000; ab49849) (both from Abcam), total AKT (\#2920), phospho-AKT

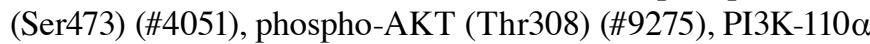
(\#4249), PI3K-110ß (\#3011) and p85 (\#4257) (dilution for all, 1:1,000; all from Cell Signaling Technology, Inc., Danvers, 
MA, USA) and $\beta$-actin rabbit monoclonal antibody (dilution, 1:2,000; \#8457; Cell Signaling Technology, Inc.) overnight at $4^{\circ} \mathrm{C}$. After washing, the membrane was incubated with the secondary antibody (dilution, 1:5,000, ab191866 and ab222759; Abcam) at room temperature for 2 h. Proteins were visualized using ECL Plus Western Blotting detection reagents (EMD Millipore) and measured using the LAS-3000 Imaging System with Fuji Image Quant software (Fuji Film, Tokyo, Japan) according to the manufacturer's instructions.

Cell proliferation assay. All cell lines were seeded and transfected in 6-well plates, and then transferred to 96-well plates at 1,000 cells per well $24 \mathrm{~h}$ following transfection. After 24, 48, 72, 96 and $120 \mathrm{~h}$ of incubation in the 96-well plates, the numbers of viable cells were detected using Cell Counting kit-8 reagents (Dojindo Laboratories, Kyushu Island, Japan), following the manufacturer's instructions. The relative viable cell numbers were measured using a microplate reader (Multiscan GO; Thermo Fisher Scientific, Waltham, MA, USA) at an absorbance optical density at $450 \mathrm{~nm}$.

Flow cytometric assay. All cell lines transfected with siRNA were seeded in 6 -well plates at $1 \times 10^{6}$ cells per well and then incubated at $37^{\circ} \mathrm{C}$ overnight. The cells were stained with propidium iodide (PI) conjugated with Annexin V-FITC (BD Biosciences, Franklin Lakes, NJ, USA) for flow cytometric analysis. First, all the cells were washed twice with cold phosphate-buffered saline and resuspended in $1 \mathrm{X}$ binding buffer. The cells were then transferred to a $5-\mathrm{ml}$ tube containing $5 \mu \mathrm{l}$ each of Annexin V-FITC and PI, and then incubated in the dark for $30 \mathrm{~min}$ at room temperature. Finally, $300 \mathrm{ml}$ of $1 \mathrm{X}$ binding buffer were added and $\sim 10,000$ apoptotic cells were collected. For cell cycle analysis, the cells treated with siRNA were incubated at $37^{\circ} \mathrm{C}$ for 48 and $72 \mathrm{~h}$, stained with PI solution in the dark for $30 \mathrm{~min}$, and then subjected to flow cytometry. Data were analyzed using FlowJo software (FlowJo, LLC, Ashland, OR, USA).

Transwell assay. Approximately $5 \times 10^{4} \mathrm{SW} 480$ cells were plated into the upper chambers (PET, 8- $\mu \mathrm{m}$ pore size) of the apparatus (Corning Inc., Corning, NY, USA) with serumfree medium. The lower chambers were filled with complete L-15 medium, supplemented with 10\% FBS. Following $48 \mathrm{~h}$ of incubation, the cells in the upper chambers were washed, fixed with $95 \%$ ethanol, and stained with $0.1 \%$ crystal violet (Sigma-Aldrich Corp.). Finally, images of the the cells that had migrated through the membrane to the lower surface of the upper chamber were captured under an inverted microscope (Nikon Corp., Tokyo, Japan).

Immunohistochemical (IHC) analysis. The tissues were fixed in $4 \%$ formalin, embedded in paraffin, and sectioned at a thickness of $4 \mu \mathrm{m}$. The sections were deparaffinized by washing several times with xylene and then rehydrated in graded alcohol solutions. The sections were permeabilized in citrate buffer (pH 6.0; Maixin Biotech Co., Ltd., Fuzhou, China) for $10 \mathrm{~min}$ and then incubated with normal goat serum for $1 \mathrm{~h}$. Subsequently, the sections were incubated with anti-HDAC3 polyclonal antibody (dilution, 1:100, ab7030) and anti-AKAP12 monoclonal antibody (dilution, 1:100, ab49849) (both from Abcam) for $1 \mathrm{~h}$ at $37^{\circ} \mathrm{C}$. The following day, the slides were washed and incubated with the corresponding secondary antibody (dilution, 1:500, ab191866; Abcam). Finally, the expression levels of HDAC 3 and AKAP12 in the non-tumor and tumor tissues were calculated: The whole immunohistochemical evaluation and scoring were performed by two independent pathologists. The staining percentages were determined by randomly selecting 4-5 fields for each tissue section, and after counting the total number of nucleus, the tissues with the numbers of positive nuclei over the 5\% total nuclei were considered as positive, or otherwise negative. In the positive group, the staining status was designated as ' + ', '++' and '+++' according to the staining density, of which ' + ' and ' ++ ' were regarded as positive-medium, whereas ' +++ ' as positive-high. Images were acquired under an inverted microscope (Nikon Corp.). All specimens were collected from patients with CRC at Huashan Hospital and Shanghai Tenth People's Hospital. Written consent was obtained from all subjects and the study protocol was approved by the Ethics Committees of Huashan Hospital and Shanghai Tenth People's Hospital.

Statistical analysis. One-way ANOVA and the $\chi^{2}$ test were used to compare differences between various groups to assess statistical significance. The gray values of the western blot bands were analyzed using ImageJ software (https:-imagej-nih-gov/ij/). Following one-way ANOVA, the LSD method was applied to further analyze two individual groups as needed. All statistical analyses were performed using SPSS 20.0 software (IBM-SPSS, Inc., Chicago, IL, USA). Probability (P)-values $<0.05$ and $<0.01$ were considered to indicate statistically significant differences.

\section{Results}

Negative correlation between HDAC 3 and AKAP12 expression in clinical CRC tissues. To investigate the expression of HDAC3 in CRC, 96 paired CRC tissues and adjacent non-cancerous tissues were subjected to IHC analysis. As shown in Fig. 1A, positive immunostaining of the HDAC3 protein was observed in the nuclei of 84 cancerous tissues. Among these positive cases, 53 (63.1\%) exhibited high expression levels and 31 (36.9\%) exhibited moderate expression levels in tumor tissues. Representative examples displaying positive HDAC3 staining indicated that the level of HDAC 3 in the CRC tissues was much higher than that in non-tumor tissues. As shown in Fig. 1C, HDAC3 protein expression was markedly upregulated in the tumor tissues $\left(\chi^{2}=5.658, \mathrm{P}=0.0174\right)$.

AKAP12 functions as a tumor suppressor gene in various types of cancer. Thus, we then examined the expression of AKAP12 in CRC tissues. Representative images of IHC-stained colorectal adenocarcinoma tissues are shown in Fig. 1B. The expression level of AKAP12 was lost in 48 (50\%) tumor tissues, 28 (29.2\%) displayed moderate expression, and only $20(20.8 \%)$ exhibited a high expression. In total, AKAP12 exhibited a lower expression in 69 (71.8\%) of the 96 tumor tissues when compared with the levels in their matched nontumor adjacent tissues, whereas all the non-cancerous tissues exhibited a relatively high AKAP12 expression (data not shown). The data obtained from IHC analysis were analyzed statistically using the $\chi^{2}$ test. As shown in Fig. 1C, AKAP12 
A HDAC3 IHC

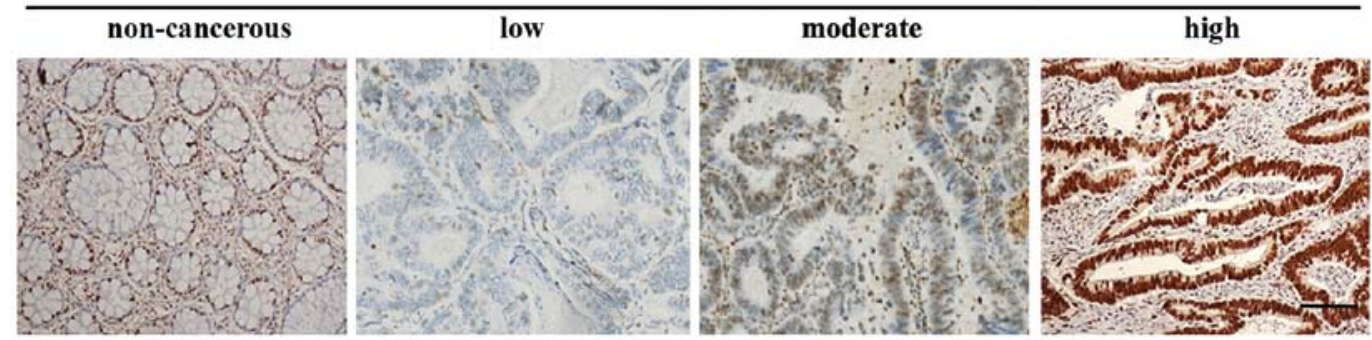

B

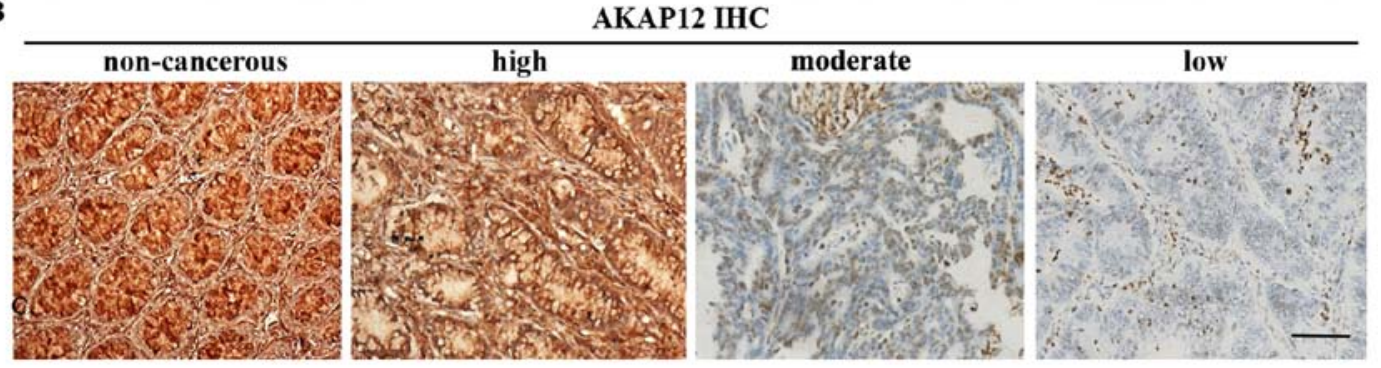

C

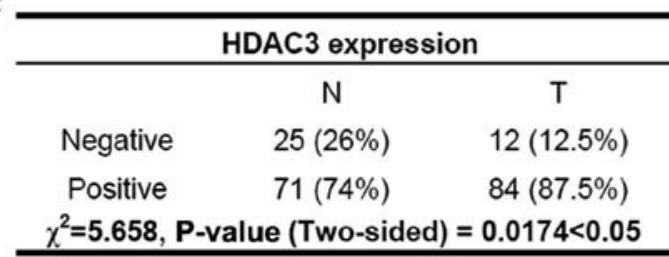

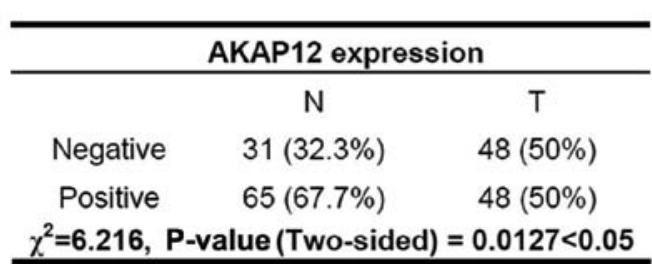

Figure 1. Representative immunostaining images of colorectal adenocarcinoma tissues. (A) HDAC3 expression in colorectal tumor tissues and adjacent noncancerous tissues was classified as low, moderate, or high. (B) The expression of AKAP12 in colorectal tumor tissues and adjacent non-cancerous tissues was also classified as low, moderate, or high. (C) The $\chi^{2}$ test was used to analyze the protein expression levels of HDAC3 $\left(\mathrm{n}=96, \chi^{2}=5.658, \mathrm{P}<0.05\right)$ and AKAP12 $\left(\mathrm{n}=96, \chi^{2}=6.216, \mathrm{P}<0.01\right)$ in tumor and non-tumorous colorectal tissues: -, negative (low); +, positive (moderate and hight). Scale bar, $100 \mu \mathrm{m}$.

protein expression was markedly decreased in the tumor tissues $\left(\chi^{2}=6.216, P=0.0127\right)$. As shown in Tables I and II, the expression of AKAP12 or HDAC3 in the tumor tissues exhibited significant differences with a number of the clinical characteristics.

Treatment with an HDAC inhibitor induces AKAP12 expression in SW480 cells. To validate the effects of HDAC3 on AKAP12 expression in CRC, the expression levels in 3 human CRC cell lines (LoVo, SW480 and LS174T) were examined by western blot analysis. TSA is a classical HDAC inhibitor, which inhibits HDACs in a non-competitive and reversible manner. TSA inhibits the proliferation and promotes the apoptosis of a variety of cancer cells, such as colorectal, prostate and breast cancer cells (29-31). Thus, TSA was applied to clarify the potential effect of HDAC3 on AKAP12. As expected, a negative correlation between HDAC 3 and AKAP12 expression was observed in all $3 \mathrm{CRC}$ cell lines (Fig. 2A and B) in the presence of TSA. The use of the HDAC3 specific inhibitor, RGFP966, markedly increased the protein level of AKAP12 in both the LoVo and SW480 cell lines (Fig. 2C). Importantly, a regulatory element containing the E/GC-box within intron-1 of the AKAP12 gene loci was first identified, and chromatin immunoprecipitation assay revealed that the presence of the $\mathrm{E}$ and GC-box (Pair-2) is indispensable for the binding of HDAC3 at intron-1 loci (Fig. 2D and E). It has been documented that $\mathrm{Sp} 1$ is also necessary for the DNA binding activity of HDAC3 (32); we thus examined the effects of Sp1 on the
HDAC3/DNA complex and found that the binding of HDAC3 with DNA was attenuated in the absence of Sp1 (Fig. 2F). More, the intron-1 of AKAp12 (wild-type or E/GC-box deleted mutant form) was inserted into the pGL3-CMV construct to verify the effects of HDAC3 on gene expression. As shown in Fig. 2G, the luciferase activity of the pGL3-CMV-AKAPIntron- 1 construct was decreased by $<50 \%$ as compared with that of the pGL3-CMV construct. However, transfection with siRNA targeting HDAC3 restored the luciferase activity. As expected, no significant changes were observed in the pGL3CMV-AKAP-Intron-mutant-transfected cells in comparison with the pGL3-CMV cells following transfection with si-NC or si-HDAC3 (Fig. 2G). Taken together, these data indicate that HDAC 3 may suppress the expression of AKAP12 by directly binding with the E/GC-box region of AKAP12 gene loci in CRC cells.

HDAC3-mediated AKAP12 downregulation promoted cell proliferation and $G 2 / M$ transition, and prevented cell apoptosis. In order to examine the biological roles of HDAC3 and AKAP12 in colorectal tumorigenesis, the expression of HDAC3, AKAP12, or HDAC3 and that of AKAP12 was suppressed via RNA interference (RNAi). The efficacy of RNAi on the SW480 cells was confirmed by RT-qPCR and western blot analysis. The most efficient siRNA was applied for the following experiments (Fig. 3A and B). As shown in Fig. 3C, transfection with si-HDAC3 resulted in the inhibition of cell proliferation, whereas transfection with si-AKAP12 
Table I. Correlation between AKAP12 expression and clinicopathological characteristics.

\begin{tabular}{|c|c|c|c|c|}
\hline Characteristic & $\begin{array}{c}\text { Total } \\
(n=96)\end{array}$ & $\begin{array}{l}\text { Negative } \\
(n=48)\end{array}$ & $\begin{array}{l}\text { Positive } \\
(\mathrm{n}=48)\end{array}$ & P-value \\
\hline Age (years) & & & & 0.8379 \\
\hline$<65$ & 45 & 23 & 22 & \\
\hline$>65$ & 51 & 25 & 26 & \\
\hline Sex & & & & 0.1530 \\
\hline Male & 49 & 21 & 28 & \\
\hline Female & 47 & 27 & 20 & \\
\hline Location & & & & 0.4332 \\
\hline Left & 45 & 25 & 20 & \\
\hline Transverse & 5 & 1 & 4 & \\
\hline Right & 27 & 12 & 15 & \\
\hline Rectum & 19 & 10 & 9 & \\
\hline T stage & & & & 0.1396 \\
\hline $\mathrm{T} 1 / 2$ & 8 & 2 & 6 & \\
\hline $\mathrm{T} 3 / 4$ & 88 & 46 & 42 & \\
\hline $\mathrm{N}$ stage & & & & $<0.0001$ \\
\hline No & 47 & 7 & 40 & \\
\hline $\mathrm{N} 1 / 2 / 3$ & 49 & 41 & 8 & \\
\hline AJCC stage (TNM) & & & & $<0.0001$ \\
\hline $\mathrm{I}+\mathrm{II}$ & 44 & 4 & 40 & \\
\hline III + IV & 52 & 44 & 8 & \\
\hline Histological grade & & & & 0.0007 \\
\hline Well & 10 & 1 & 9 & \\
\hline Medium & 71 & 34 & 37 & \\
\hline Poor & 15 & 13 & 2 & \\
\hline $\begin{array}{l}\text { Venous and } \\
\text { lymphatic metastasis }\end{array}$ & & & & $<0.0001$ \\
\hline No & 47 & 7 & 40 & \\
\hline Yes & 49 & 41 & 8 & \\
\hline Liver metastasis & & & & 0.0154 \\
\hline No & 86 & 39 & 47 & \\
\hline Yes & 10 & 9 & 1 & \\
\hline
\end{tabular}

treatment led to an increase in cell proliferation. Of note, the co-silencing of HDAC3 and AKAP12 yielded a similar result as that observed with transfection with si-AKAP12, suggesting that HDAC3 may promote cell proliferation by negatively regulating the expression of AKAP12. Similarly, the results of a colony formation assay revealed that transfection with si-HDAC3 inhibited the growth of the colorectal cells, whereas transfection with si-AKAP12 or si-HDAC3 together with si-AKAP12 markedly increased the number and size of colonies in vitro (Fig. 3D).

Based on the observation that the silencing of AKAP12 or AKAP12 with that of HDAC3 induced cell proliferation and colony formation, the anti-apoptotic activity of the CRC cells was investigated. As shown in Fig. 3E, the percentage of apoptotic cells was much lower following HDAC3 and AKAP12 co-silencing or AKAP12 silencing alone, as compared with
Table II. Correlation between HDAC3 and clinicopathological characteristics.

\begin{tabular}{|c|c|c|c|c|}
\hline Characteristic & $\begin{array}{c}\text { Total } \\
(\mathrm{n}=96)\end{array}$ & $\begin{array}{l}\text { Negative } \\
(n=12)\end{array}$ & $\begin{array}{l}\text { Positive } \\
(\mathrm{n}=84)\end{array}$ & P-value \\
\hline Age (years) & & & & 0.3149 \\
\hline$<65$ & 45 & 4 & 41 & \\
\hline$>65$ & 51 & 8 & 43 & \\
\hline Sex & & & & 0.9385 \\
\hline Male & 49 & 6 & 43 & \\
\hline Female & 47 & 6 & 41 & \\
\hline Location & & & & 0.1337 \\
\hline Left & 45 & 6 & 39 & \\
\hline Transverse & 5 & 2 & 3 & \\
\hline Right & 27 & 1 & 26 & \\
\hline Rectum & 19 & 3 & 16 & \\
\hline T stage & & & & 0.0008 \\
\hline $\mathrm{T} 1 / 2$ & 8 & 4 & 4 & \\
\hline $\mathrm{T} 3 / 4$ & 88 & 8 & 80 & \\
\hline $\mathrm{N}$ stage & & & & 0.0016 \\
\hline N0 & 47 & 11 & 36 & \\
\hline $\mathrm{N} 1 / 2 / 3$ & 49 & 1 & 48 & \\
\hline AJCC stage (TNM) & & & & 0.0053 \\
\hline $\mathrm{I}+\mathrm{II}$ & 44 & 10 & 34 & \\
\hline $\mathrm{III}+\mathrm{IV}$ & 52 & 2 & 50 & \\
\hline Histological grade & & & & 0.0004 \\
\hline Well & 10 & 5 & 5 & \\
\hline Moderately & 71 & 7 & 64 & \\
\hline Poor & 15 & 0 & 15 & \\
\hline $\begin{array}{l}\text { Venous and lymphatic } \\
\text { metastasis }\end{array}$ & & & & 0.0016 \\
\hline No & 47 & 11 & 36 & \\
\hline Yes & 49 & 1 & 48 & \\
\hline Liver metastasis & & & & 0.2067 \\
\hline No & 86 & 12 & 74 & \\
\hline Yes & 10 & 0 & 10 & \\
\hline
\end{tabular}

that observed with si-HDAC3 silencing alone by applying PI and Annexin V staining. Moreover, flow cytometric analysis revealed an increased proportion of cells in the $\mathrm{G} 2 / \mathrm{M}$ phase and a slight reduction in the number of cells in the G1 phase following transfection with si-AKAP12 or si-HDAC3 together with si-AKAP12 (Fig. 3F). Taken together, these results indicate that HDAC3 may function as a pro-tumor gene by inhibiting AKAP12 expression in CRC.

Negative regulation of cell migration by AKAP12. To further assess the role of AKAP12 in cell migration, Transwell assays were performed to examine cell migration following HDAC3 and AKAP12 knockdown. As shown in Fig. 4, the number of metastatic cells was markedly decreased following transfection with si-HDAC3, whereas transfection with si-AKAP12 or with both si-AKAP12 and si-HADC3 enhanced cell metastasis in vitro. 
A

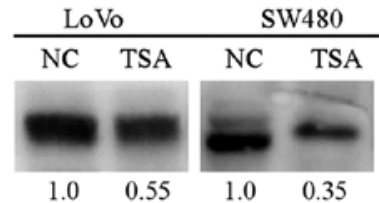

HDAC 3

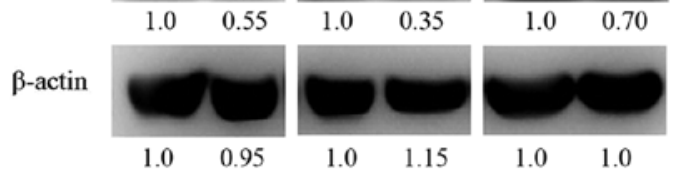

C

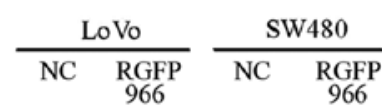

AKAP12

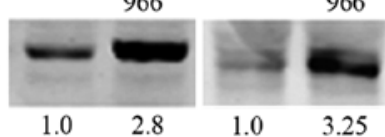

$\beta$-actin

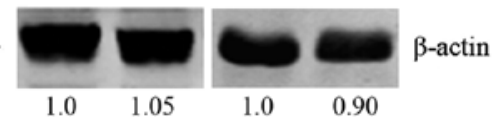

B

KAP12

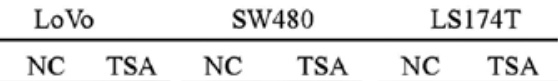

$\beta$-actin
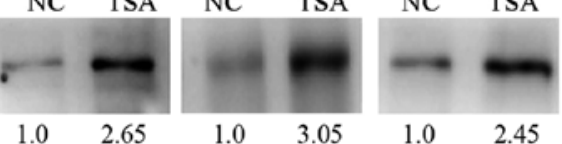

(2)

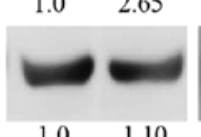

$1.0 \quad 3.05$

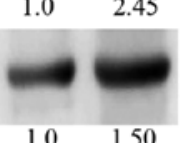

D

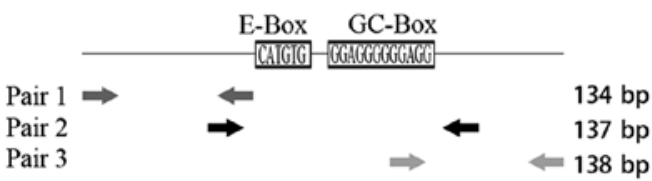

$\mathrm{E}$

F
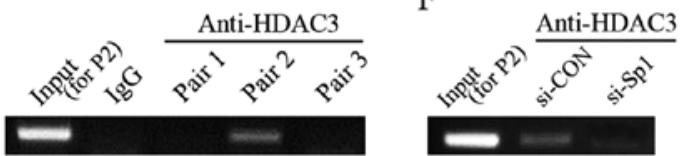

G

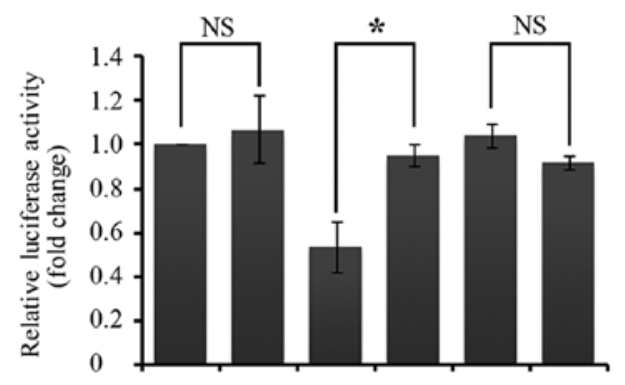

$\begin{array}{ccccccc}\underset{\text { pGL3-CMV }}{\text { pGL3-CMV-AKAP }} & + & + & - & - & - & - \\ \begin{array}{c}\text {-Intron-1 } \\ \text { pGL3-CMV-AKAP- }\end{array} & - & - & + & + & - & - \\ \begin{array}{c}\text { Intron-Mutant } \\ \text { si-NC }\end{array} & + & - & - & - & + & + \\ \text { si-HDAC3 } & - & + & - & + & - & +\end{array}$

Figure 2. The expression of HDAC3 and AKAP12 at the mRNA and protein level in 3 CRC cell lines following TSA (500 ng/ml) treatment. (A and B) Protein levels of HDAC3 and AKAP12 at $24 \mathrm{~h}$ following TSA treatment in 3 cell lines (LoVo, SW480 and LS174T) were examined by western blot analysis. Representative results from experiments conducted in triplicate. Data are presented as the means \pm standard deviation (SD). (C) LoVo and SW480 cells were further treated with an HDAC3 specific inhibitor, RGFP966. The protein level of AKAP12 was examined by western blot analysis. (D) Schematic diagram of AKAP12 intron-1 region containing E and GC boxes, and 3 primer pairs (named as pair-1, pair-2 and pair-3) used to amplify HDAC3 binding region. (E and F) ChIP assay was performed to examined the binding of HDAC3 at intron-1 loci. (G) Luciferase assay was carried out to examine the regulatory effects of AKAP-intron-1 on luciferase activity. Data are presented as the means \pm SD. One-way ANOVA: ${ }^{*} \mathrm{P}<0.05$; NS, no significant difference.

Increased protein levels of $p$-AKT in response to transfection iwth si-AKAP12 are necessary for colony formation and migration. Previous findings on endothelial cells have suggested that the tumor suppressor gene, AKAP12, is epigenetically regulated by $\mathrm{HDAC} 7$, which may regulate STAT3 (33). Other data have also shown that HDAC3 modulates the JAK/STAT3 pathway in multiple myeloma cells (34). Thus, the ability of HDAC3 to enhance cell malignant phenotypes via the modulation of the AKAP12-JAK-STAT3 axis was investigated. We found no significant changes in STAT3 signaling upon HDAC3 or AKAP12 knockdown in the CRC cells (data not shown). As the PI3K/AKT pathway has been widely documented as the major pathway involved in tumor progression by controlling cell proliferation, apoptosis, aggressiveness and metastasis (35), the level of p-AKT in the CRC cells was examined. The results revealed that transfection with si-HDAC3 decreased the level of p-AKT. Moreover, the expression level of p-AKT was significantly increased in response to si-AKAP12 transfection. Importantly, transfection with si-AKAP12 reversed the si-HDAC-3-mediated inactivation of AKT (Fig. 5A).

Mechanistically, no significant changes in the levels of PI3K subunits, including PI3K-110 $\alpha$, PI3K-110 $\beta$ and p85, were observed following transfection with si-AKAP12 or si-AKAP12 plus si-HDAC3 in comparison to transfection with si-NC (Fig. 5A). Of note, the level of phosphorylated p85, a regulatory subunit of $\mathrm{PI} 3 \mathrm{~K}$, was increased in cells transfected with si-AKAP12 or si-AKAP12 together with si-HDAC3, indicating that the underlying mechanisms may involve AKAP12-regulated AKT activity. In addition, the expression of the anti-apoptotic protein, Bcl-2, was increased in response to si-AKAP12 transfection, suggesting that increased Bcl-2 expression may be necessary for AKAP12-mediated cell apoptosis (Fig. 5B). 
A
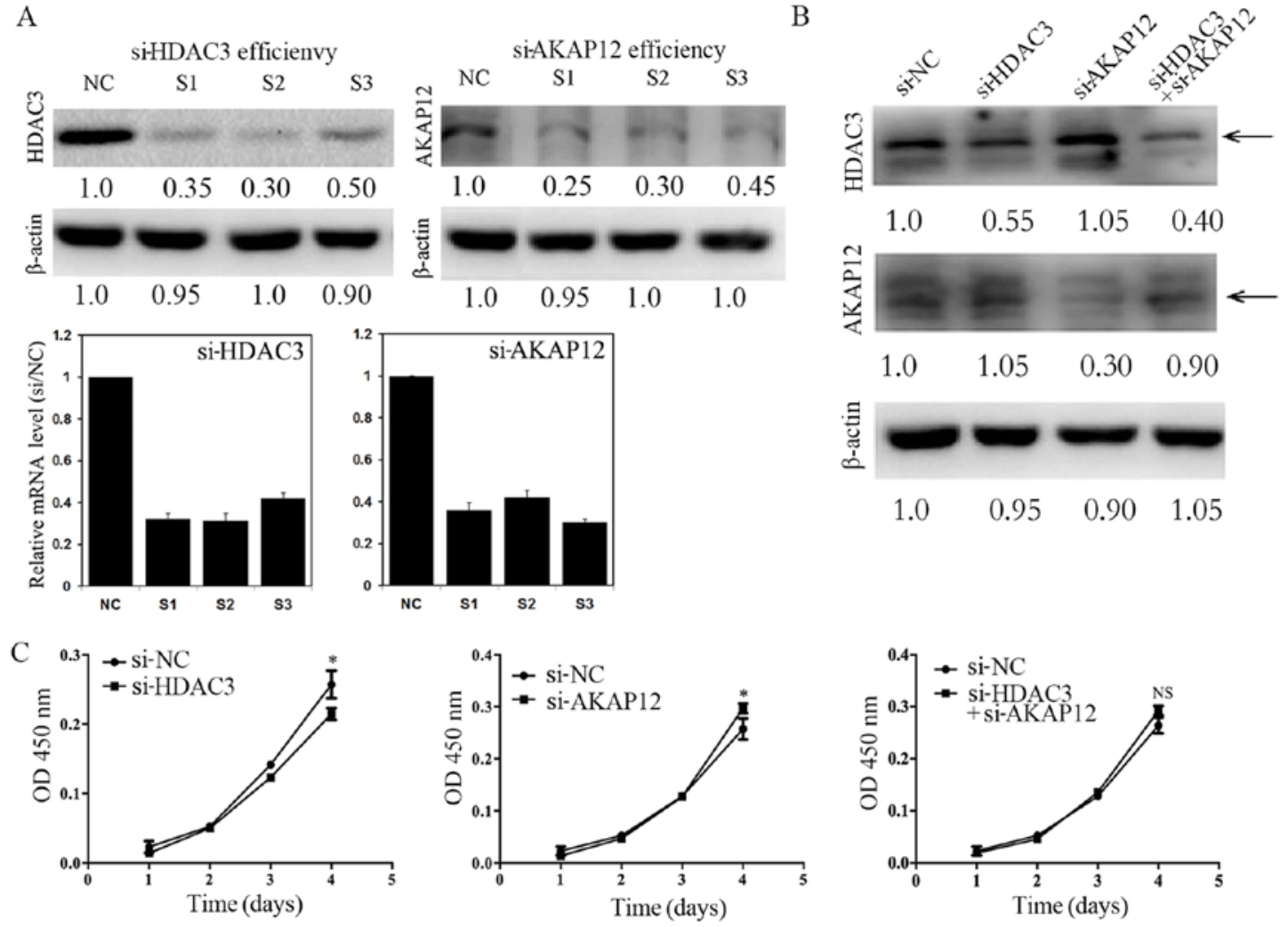

$\mathrm{D}$
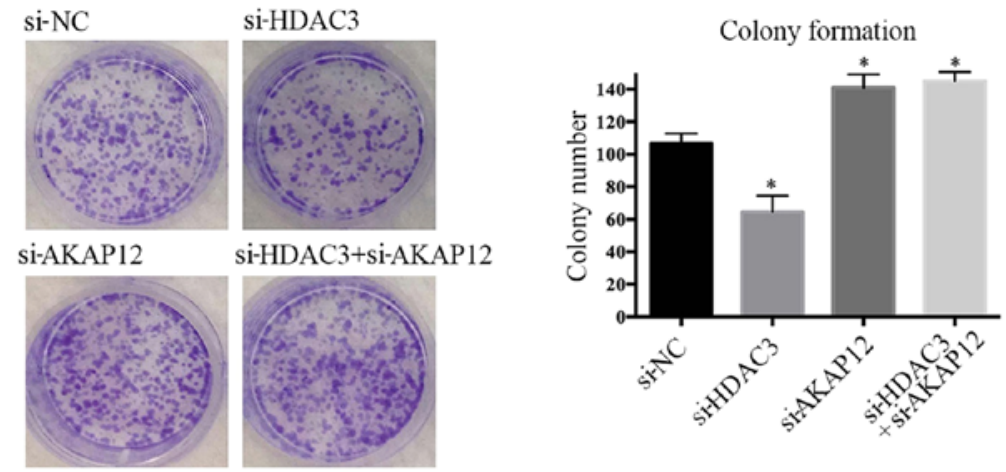

E
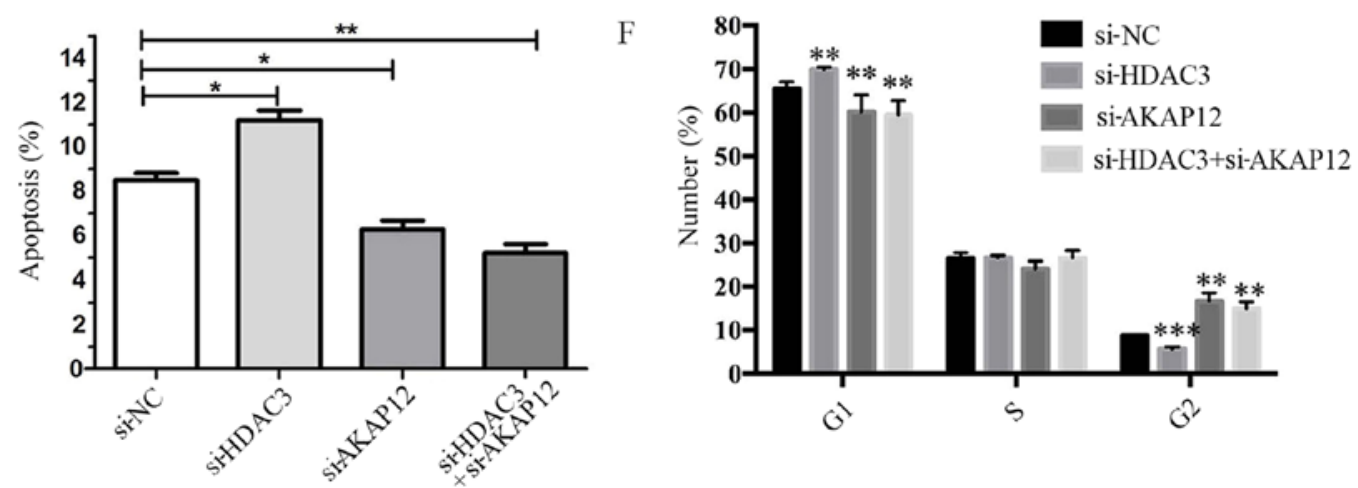

Figure 3. HDAC3 and AKAP12 co-silencing inhibit the proliferation, induce apoptosis, and promote G2/M checkpoint arrest in SW480 cells. (A and B) The expression of HDAC3 and AKAP12 in SW480 cells transfected with siRNA was detected by RT-qPCR ( $24 \mathrm{~h}$, lower panel) and western blot analysis (48 h, upper panel). (C) The growth of SW480 cells after the silencing of HDAC3 and AKAP12 was examined by CCK-8 assay on the indicated days. Significant differences were found after the co-silencing of HDAC3 and AKAP12. (D) The SW480 cells, following silencing of HDAC3 and AKAP12, were subjected to colony formation assays following transfection and culture for 14 days. (E) The SW480 cells, after the silencing of HDAC3 and AKAP12, were subjected to flow cytometry to examine cell apoptosis. All experiments were performed in triplicate. (F) The SW480 cells, after the silencing of HDAC3 and AKAP12, were cultured in an incubator for $48 \mathrm{~h}$ and subjected to flow cytometric analysis. Data are presented as the means \pm SD. One-way ANOVA test: " $\mathrm{P}<0.05$; ${ }^{* *} \mathrm{P}<0.01 ;{ }^{* * *} \mathrm{P}<0.001 ; \mathrm{NS}$, no significant difference.

To further verify the potential effects of AKT signaling on the regulation of the cell phenotype by AKAP12, two inhibitors specifically targeting AKT, MK2206 and AZD5363, were applied in the presence of si-HDAC3, si-AKAP12 or si-HDAC3 

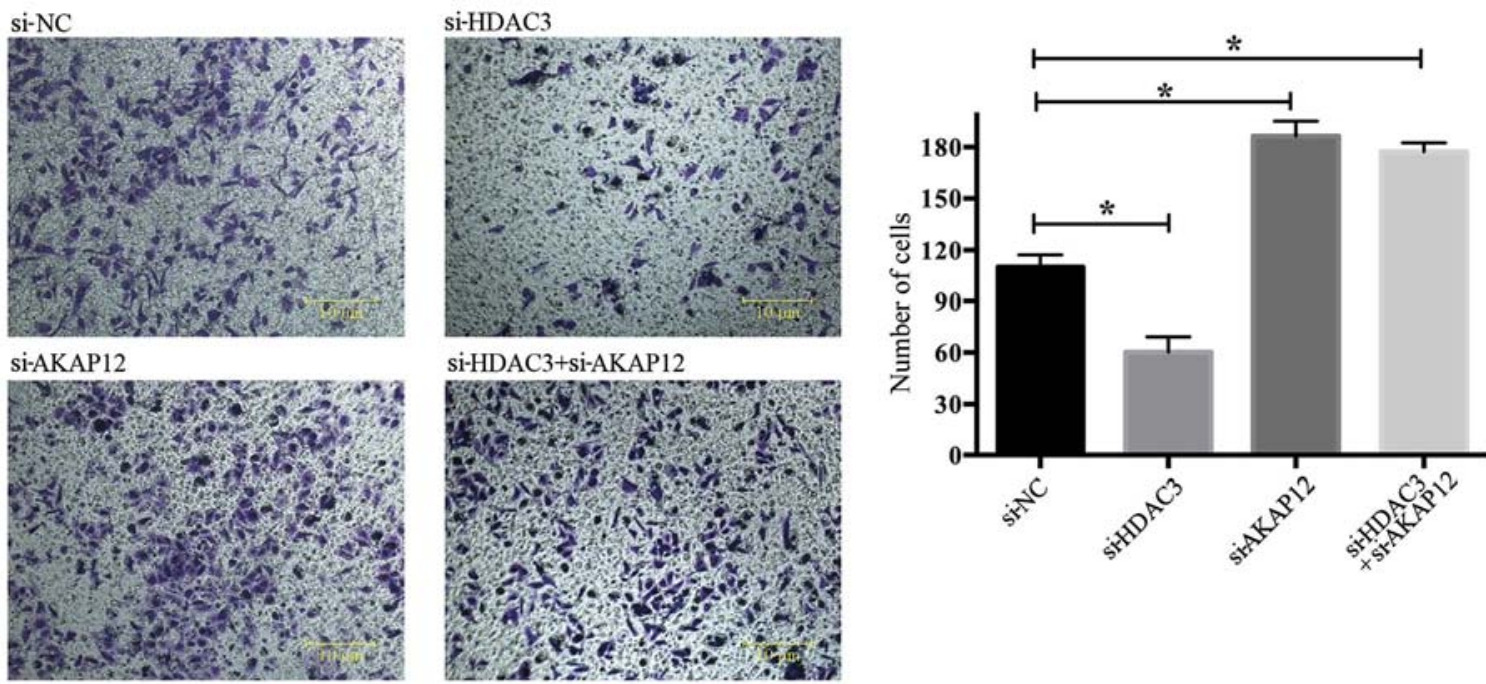

Figure 4. HDAC 3 and AKAP12 co-silencing inhibits the migration of SW480 cells. The SW480 cells, after the silencing HDAC3 and AKAP12, were subjected to Transwell assay. All experiments were performed in triplicate and data are presented as the means \pm SD. One-way ANOVA test: ${ }^{*}<0.05$

plus si-AKAP12 in the SW480 cells. Both colony formation and migration assay revealed that the use of the AKT inhibitors significantly reduced the number of colonies and migrating cells in the si-AKAP12 group and in the si-HDAC3 plus si-AKAP12 group in comparison with the si-NC group (Fig. 5C and D). In addition, we also found the exogenous expression of AKT restored si-HDAC3-modulated cell migration in an AKAP12dependent manner (Fig. 5E). Mechanistically, the decreased expression of MMP2 and MMP7 and the increased expression of TIMP2 was observed following transfection with si-HDAC3, and this effect was by transfection with si-AKAP12 simultaneously (Fig. 5F). Further, transfection with siRNA against Bcl-2 sensitized the cells to cisplatin-induced caspase-3 cleavage and cell apoptosis in both the si-AKAP12 and si-HDAC3-plus si-AKAP12-transfected cells (Fig. 5G). Taken together with the data from two primary CRC cells (Fig. $5 \mathrm{H}$ ), it was thus suggested that HDAC3-AKAP12 manipulate cell malignant phenotypes via the PI3K/AKT/MMP pathway and the Bcl-2 gene in CRC cells.

\section{Discussion}

Numerous studies have demonstrated that AKAP12 is epigenetically reduced or lost in many types of cancer, including prostate cancer (36), ovarian cancer (37), hepatocellular cancer (38), CRC (39) and acute myeloid leukemia (9). However, the biological roles of AKAP12 in CRC progression and the intrinsic mechanisms of AKAP12 depletion associated with the progression of CRC are not yet completely understood. The results of the present study provide evidence that AKAP12 functions as a tumor suppressor in CRC. First, the expression profiles of AKAP12 were examined at both the mRNA and protein levels, and the results revealed a significant upregulation following TSA treatment. Second, AKAP12 was found to significantly inhibit CRC cell growth and migration, while promoting apoptotic cell death.

Emerging studies have demonstrated a deficiency in AKAP12, which plays an important role in tumor progression and metastasis, in many types of cancer (40-44). In human gastric cancer cells, AKAP12 can lead to reduced colony formation and the induction of cell apoptosis (40). Consistent with the findings of previous studies, in this study, AKAP12 expression was downregulated in 45 (46.9\%) of 96 CRC tissues as compared with their matched non-tumor tissues in this study. The proliferation and apoptosis of the SW480 cells was then investigated to evaluate the potential regulatory effects of AKAP12 on CRC cells by CCK- 8 assay and flow cytometry. The results revealed a potentially suppressive role of AKAP12 in the development of CRC.

The HDAC family of transcriptional co-repressors, which regulates a large variety of genes and functional regulatory proteins, has emerged as an important regulator of maturation and transformation. The overexpression of HDACs is a well-documented phenomenon in a number of malignancies, particularly in CRC (9-15). A recent meta-analysis of a variety of human cancers indicated that HDAC 3 may be one of the most frequently upregulated genes in cancer cells (45). The overexpression of HDAC3 reportedly has the capability to inhibit basal and butyrate-induced p21 transcription in a Sp1/Sp3-dependent manner, whereas the silencing of HDAC3 stimulates $\mathrm{p} 21$ promoter activity and expression (32). Godman et al found that HDAC3 knockdown significantly suppressed $\beta$-catenin translocation from the plasma membrane to the nucleus in the Wnt and vitamin D signaling pathway (20). In addition, HDAC 3 also specifically inhibited NF- $\kappa \mathrm{B}$-mediated cell metastasis via interacting with CREB3 (22). Similarly, the findings of the present study suggested that HDAC3 knockdown induced apoptotic cell death, inhibited cell growth, and decreased the ability of CRC cells to metastasize. Therefore, HDAC3 may be regarded as a biological marker for the prediction of metastasis in CRC.

In the present study, the association between HDAC3 and AKAP12 in CRC cells was examined. First, a significant negative correlation between AKAP12 and HDAC3 in CRC was found. AKAP12 expression was increased prominently following treatment with the HDAC inhibitor, TSA, suggesting that deacetylation may play a key role in the downregulation of AKAP12 expression in CRC. Generally, HDAC manipulates 
A

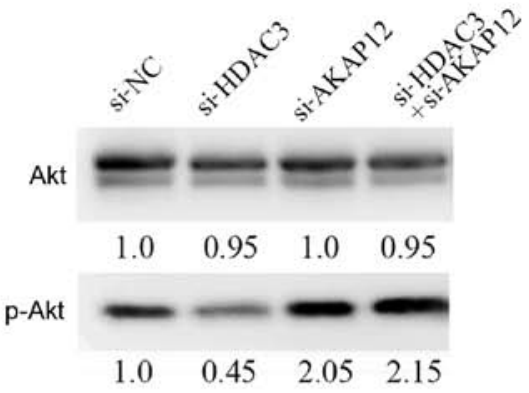

PI3K-110a

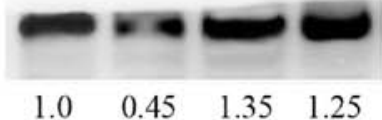

PI3K-110 $\beta$
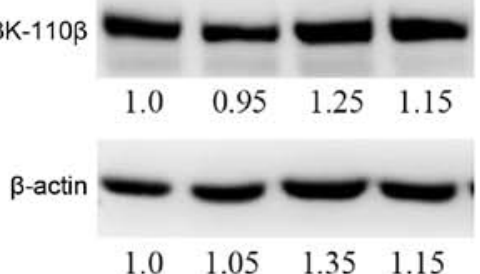

$\mathrm{C}$

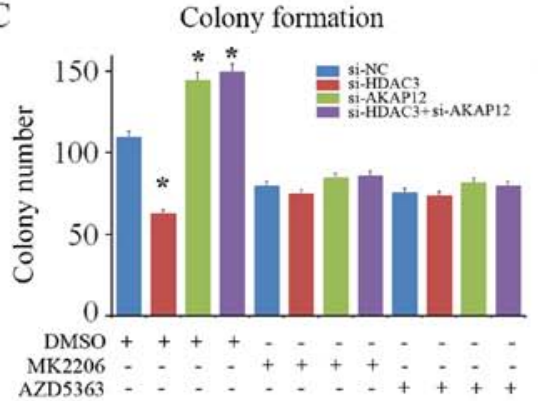

E

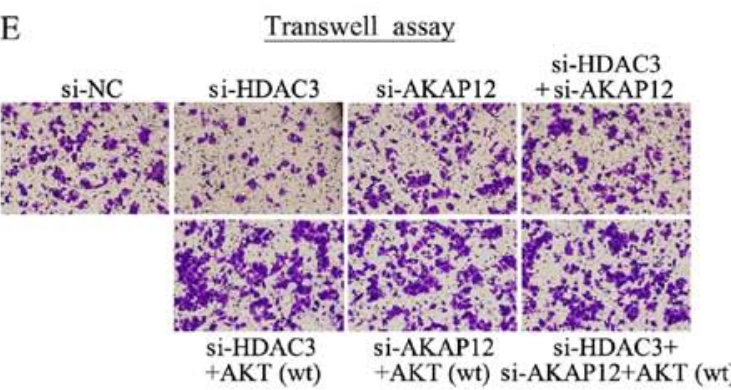

G

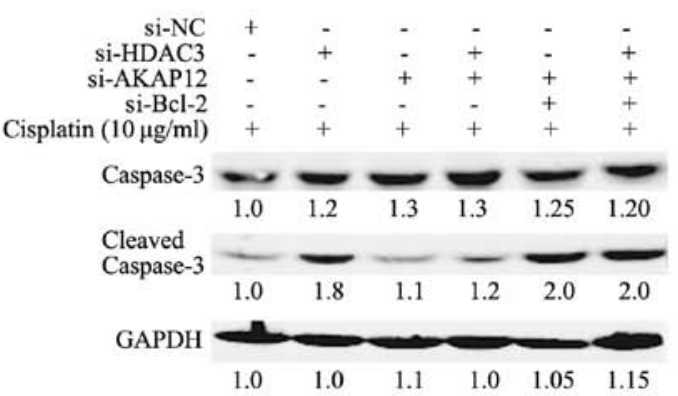

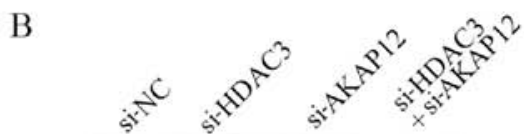

Bcl-2

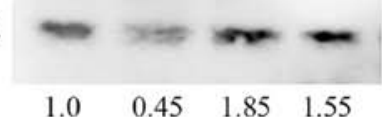

p85

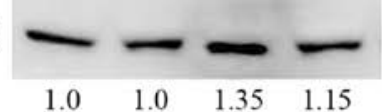

p-p85

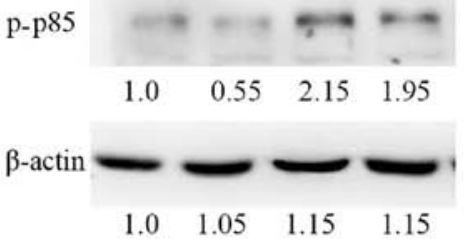

D Cell migration

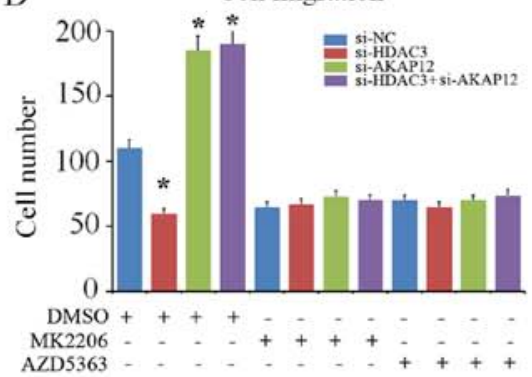

F

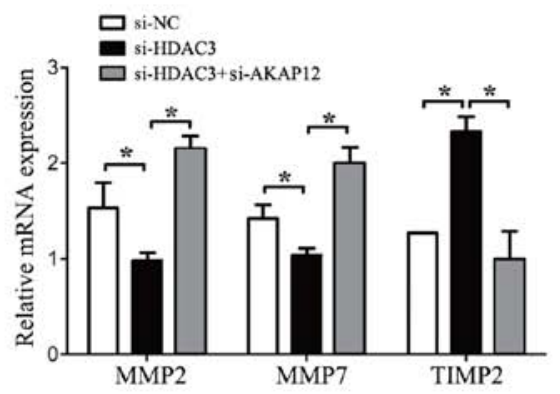

$\mathrm{H}$

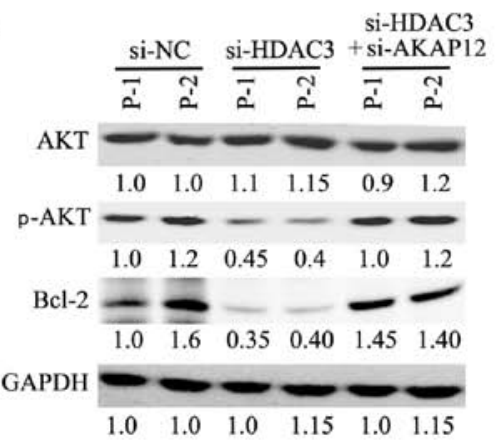

Figure 5. Upregulation of AKAP12 expression attenuates AKT activation and the expression of Bcl-2 in SW480 cells. (A) AKT expression and phosphorylation levels following HDAC3 and AKAP12 co-silencing and silencing alone in SW480 cells. Co-silencing of HDAC3 and AKAP12 decreased p-AKT protein expression at the Thr308 residue and AKAP12 silencing alone increased p-AKT levels. (B) The expression of the anti-apoptotic protein, Bcl-2, p85 and phosphorylated p 85 were examined by western blot analysis. (C and D) Two AKT inhibitors were applied to verify the effects of AKAP12 on cell colony formation or migration following transfection with si-HDAC3 or si-AKAP12. (E) Transwell assay was performed to examine the effect of exogenously expressed AKT on cells transfected with si-HDAC3, si-AKAP12 or si-HDAC3 plus si-AKAP12. (F) The mRNA levels of MMP2, MMP7 and TIMP2 were examined after si-HDAC3, si-HDAC3 plus si-AKAP12 transfection by RT-qPCR assay. (G) After $48 \mathrm{~h}$ of transfection, the cells were treated with cisplatin (10 $\mu \mathrm{g} / \mathrm{ml})$ for an additional $16 \mathrm{~h}$. Western blot analysis was performed to evaluated the expression of caspase-3 and cleaved caspase-3. (H) Two primary CRC cells isolated from clinical tumor samples were used. All experiments were performed in triplicate and the data are presented as the means \pm SD. One-way ANOVA test: ${ }^{*} \mathrm{P}<0.05$. 
transcriptional activity through binding with the DNA sequences beside or upstream the transcription start site. It is noteworthy that we found that the binding of the HDAC over AKAP12 intron led to the transcriptional suppression by ChIP and luciferase assay. We hence speculated that some co-factors or unknown chromosome architecture may be involved. Further studies are warranted to explore the potential mechanisms involved.

The PI3K/AKT pathway is a major contributor to CRC progression $(35,46)$. PI3K/AKT can be recruited and stimulated by the serine/threonine kinases PKD1 and AKT, whereby PKD1 phosphorylates AKT on threonine 308 and a second phosphorylation, catalyzed by mTORC2, on serine 473 activates AKT. AKT provides signals that lead to cell growth and differentiation, and angiogenesis. It prevents apoptosis in CRC as phosphorylated AKT stimulates a multitude of downstream targets, such as BAD, mTOR, FOXO proteins, MDM2 and VEGF, with the exception of the tumor suppressors, PTEN and GSK-3 $\beta$. A previous study illustrated that HDAC inhibition exerted concentration-dependent anti-proliferative effects in CRC cells, when combined with an EGFR/HER2 kinase inhibitor, via the RAS/RAF/MEK/MAPK and PI3K/AKT pathways (47). Ye et al (48) found that the tumor suppressor, PIB5PA, blocked AKT activation via the downregulation of phosphorylation of the serine 473 residue, and mediated HDAC2 and HDAC3 hypoacetylation levels by binding to the $\mathrm{Sp} 1$ transcription promoter. In line with previous studies, the findings of the present study suggested that the co-silencing of HDAC3 and AKAP12 increased the level of AKT phosphorylation, similar to the results achieved by AKAP12 knockdown alone. These findings indicate a negative regulatory effect of AKAP12 on the PI3K/AKT signaling pathway.

In summary, these findings demonstrate that AKAP12, which is epigenetically regulated by $\mathrm{HDAC} 3$, is a suppressive regulator with the capability to inhibit cell growth and migration, and promote the apoptosis of CRC cells. Moreover, the downregulation of AKAP12 by HDAC3 is indispensable for HDAC3-induced PI3K/AKT activation and consequent cell metastasis. Further studies are warranted to clarify the underlying mechanisms of AKAP12-induced PI3K/AKT activation in CRC.

\section{Acknowledgements}

The authors would like to thank the Department of Pathology, Huashan Hosiptal affiliated to Fudan University and the Shanghai Tenth People's Hospital affiliated to Tongji University for providing the CRC specimens.

\section{Funding}

This study was supported by grants from the Outstanding Young Talent Plan of Shanghai (grant no. XYQ2013095), the National Science Foundation (grant nos. 81370067 and 81572061) and a grant from Shanghai Shenkang Hospital Development Center (grant no. SHDC22014006).

\section{Availability of data and materials}

The analyzed data sets generated during the study are available from the corresponding author on reasonable request.

\section{Authors' contributions}

WWL and FYS mainly designed the research. PH and KL mainly performed the research. SBL and MG analyzed the data and TTH helped to collect the data. All authors have read and approved the final manuscript.

\section{Ethics approval and consent to participate}

Written consent was obtained from all subjects and the study protocol was approved by the Ethics Committees of Huashan Hospital and Shanghai Tenth People's Hospital.

\section{Consent for publication}

Not applicable.

\section{Competing interests}

The authors declare that they have no competing interests.

\section{References}

1. Ellina MI, Bouris P, Aletras AJ, Theocharis AD, Kletsas D and Karamanos NK: EGFR and HER2 exert distinct roles on colon cancer cell functional properties and expression of matrix macromolecules. Biochim Biophys Acta 1840: 2651-2661, 2014.

2. Kim HJ, Yu MH, Kim H, Byun J and Lee C: Noninvasive molecular biomarkers for the detection of colorectal cancer. BMB Rep 41: 685-692, 2008.

3. Gordon T, Grove B, Loftus JC, O'Toole T, McMillan R, Lindstrom $\mathrm{J}$ and Ginsberg MH: Molecular cloning and preliminary characterization of a novel cytoplasmic antigen recognized by myasthenia gravis sera. J Clin Invest 90: 992-999, 1992.

4. Nauert JB, Klauck TM, Langeberg LK and Scott JD: Gravin, an autoantigen recognized by serum from myasthenia gravis patients, is a kinase scaffold protein. Curr Biol 7: 52-62, 1997.

5. Finger EC, Castellini L, Rankin EB, Vilalta M, Krieg AJ, Jiang D, Banh A, Zundel W, Powell MB and Giaccia AJ: Hypoxic induction of AKAP12 variant 2 shifts PKA-mediated protein phosphorylation to enhance migration and metastasis of melanoma cells. Proc Natl Acad Sci USA 112: 4441-4446, 2015.

6. Lee SW, Kim WJ, Choi YK, Song HS, Son MJ, Gelman IH, Kim YJ and Kim KW: SSeCKS regulates angiogenesis and tight junction formation in blood-brain barrier. Nat Med 9: 900-906, 2003.

7. Liu W, Guan M, Su B, Ye C, Li J, Zhang X, Liu C, Li M, Lin Y and Lu Y: Quantitative assessment of AKAP12 promoter methylation in colorectal cancer using methylation-sensitive high resolution melting: Correlation with Duke's stage. Cancer Biol Ther 9: 862-871, 2010.

8. Agrawal A, Murphy RF and Agrawal DK: DNA methylation in breast and colorectal cancers. Mod Pathol 20: 711-721, 2007.

9. Mostafa MR, Yahia RS, Abd El Messih HM, El-Sisy E and El Ghannam DM: Gravin gene expression in acute myeloid leukemia. Med Oncol 30: 548, 2013.

10. Guan M, Zhou X, Soulitzis N, Spandidos DA and Popescu NC: Aberrant methylation and deacetylation of deleted in liver cancer-1 gene in prostate cancer: Potential clinical applications. Clin Cancer Res 12: 1412-1419, 2006.

11. Jin Z, Hamilton JP, Yang J, Mori Y, Olaru A, Sato F, Ito T, Kan T, Cheng Y, Paun B, et al: Hypermethylation of the AKAP12 promoter is a biomarker of Barrett's-associated esophageal neoplastic progression. Cancer Epidemiol Biomarkers Prev 17: 111-117, 2008.

12. Sikandar S, Dizon D, Shen X, Li Z, Besterman J and Lipkin SM: The class I HDAC inhibitor MGCD0103 induces cell cycle arrest and apoptosis in colon cancer initiating cells by upregulating Dickkopf-1 and non-canonical Wnt signaling. Oncotarget 1: 596-605, 2010. 
13. Richon VM, Sandhoff TW, Rifkind RA and Marks PA: Histone deacetylase inhibitor selectively induces p21WAF1 expression and gene-associated histone acetylation. Proc Natl Acad Sci USA 97: 10014-10019, 2000.

14. Spurling CC, Godman CA, Noonan EJ, Rasmussen TP, Rosenberg DW and Giardina C: HDAC3 overexpression and colon cancer cell proliferation and differentiation. Mol Carcinog 47: 137-147, 2008.

15. Weichert W, Röske A, Gekeler V, Beckers T, Ebert MP, Pross M, Dietel M, Denkert C and Röcken C: Association of patterns of class I histone deacetylase expression with patient prognosis in gastric cancer: A retrospective analysis. Lancet Oncol 9: 139-148, 2008.

16. Wu J, Du C, Lv Z, Ding C, Cheng J, Xie H, Zhou L and Zheng S: The up-regulation of histone deacetylase 8 promotes proliferation and inhibits apoptosis in hepatocellular carcinoma. Dig Dis Sci 58: 3545-3553, 2013.

17. Soung YH, Pruitt K and Chung J: Epigenetic silencing of ARRDC3 expression in basal-like breast cancer cells. Sci Rep 4: 3846, 2014.

18. Lovaas JD, Zhu L, Chiao CY, Byles V, Faller DV and Dai Y: SIRT1 enhances matrix metalloproteinase-2 expression and tumor cell invasion in prostate cancer cells. Prostate 73: 522-530, 2013.

19. Heller G, Schmidt WM, Ziegler B, Holzer S, Müllauer L, Bilban M, Zielinski CC, Drach J and Zöchbauer-Müller S: Genome-wide transcriptional response to 5-aza-2'-deoxycytidine and trichostatin a in multiple myeloma cells. Cancer Res 68: 44-54, 2008.

20. Godman CA, Joshi R, Tierney BR, Greenspan E, Rasmussen TP Wang HW, Shin DG, Rosenberg DW and Giardina C: HDAC3 impacts multiple oncogenic pathways in colon cancer cells with effects on Wnt and vitamin D signaling. Cancer Biol Ther 7: 1570-1580, 2008.

21. Wu MZ, Tsai YP, Yang MH, Huang $\mathrm{CH}$, Chang SY, Chang CC, Teng SC and Wu KJ: Interplay between HDAC3 and WDR5 is essential for hypoxia-induced epithelial-mesenchymal transition. Mol Cell 43: 811-822, 2011.

22. Kim HC, Choi KC, Choi HK, Kang HB, Kim MJ, Lee YH, Lee OH, Lee J, Kim YJ, Jun W, et al: HDAC3 selectively represses CREB3-mediated transcription and migration of metastatic breast cancer cells. Cell Mol Life Sci 67: 3499-3510, 2010.

23. Guenther MG, Barak O and Lazar MA: The SMRT and N-CoR corepressors are activating cofactors for histone deacetylase 3 . Mol Cell Biol 21: 6091-6101, 2001

24. Togi S, Kamitani S, Kawakami S, Ikeda O, Muromoto R, Nanbo A and Matsuda T: HDAC3 influences phosphorylation of STAT3 at serine 727 by interacting with PP2A. Biochem Biophys Res Commun 379: 616-620, 2009.

25. Das $\mathrm{C}$ and Kundu TK: Transcriptional regulation by the acetylation of nonhistone proteins in humans - a new target for therapeutics. IUBMB Life 57: 137-149, 2005.

26. Arocho A, Chen B, Ladanyi M and Pan Q: Validation of the 2-DeltaDeltaCt calculation as an alternate method of data analysis for quantitative PCR of BCR-ABL P210 transcripts. Diagn Mol Pathol 15: 56-61, 2006.

27. Livak KJ and Schmittgen TD: Analysis of relative gene expression data using real-time quantitative PCR and the 2(-Delta Delta C(T)) method. Methods 25: 402-408, 2001.

28. Yang Y, Lin X, Lu X, Luo G, Zeng T, Tang J, Jiang F, Li L, Cui $\mathrm{X}$, Huang $\mathrm{W}$, et al: Interferon-microRNA signalling drives liver precancerous lesion formation and hepatocarcinogenesis. Gut 65: 1186-1201, 2016.

29. Wang X, Xu J, Wang H, Wu L, Yuan W, Du J and Cai S: Trichostatin A, a histone deacetylase inhibitor, reverses epithelialmesenchymal transition in colorectal cancer SW480 and prostate cancer PC3 cells. Biochem Biophys Res Commun 456: 320-326, 2015.

30. Fortson WS, Kayarthodi S, Fujimura Y, Xu H, Matthews R, Grizzle WE, Rao VN, Bhat GK and Reddy ES: Histone deacetylase inhibitors, valproic acid and trichostatin-A induce apoptosis and affect acetylation status of p53 in ERG-positive prostate cancer cells. Int J Oncol 39: 111-119, 2011.

31. Chatterjee N, Wang WL, Conklin T, Chittur S and Tenniswood M: Histone deacetylase inhibitors modulate miRNA and mRNA expression, block metaphase, and induce apoptosis in inflammatory breast cancer cells. Cancer Biol Ther 14: 658-671, 2013.
32. Wilson AJ, Byun DS, Popova N, Murray LB, L'Italien K, Sowa Y, Arango D, Velcich A, Augenlicht LH and Mariadason JM: Histone deacetylase 3 (HDAC3) and other class I HDACs regulate colon cell maturation and p 21 expression and are deregulated in human colon cancer. J Biol Chem 281: 13548-13558, 2006.

33. Turtoi A,Mottet D, Matheus N,Dumont B,Peixoto P, Hennequière V, Deroanne C, Colige A, De Pauw E, Bellahcène A, et al: The angiogenesis suppressor gene AKAP12 is under the epigenetic control of HDAC7 in endothelial cells. Angiogenesis 15: 543-554, 2012.

34. Minami J, Suzuki R, Mazitschek R, Gorgun G, Ghosh B, Cirstea D, Hu Y, Mimura N, Ohguchi H, Cottini F, et al: Histone deacetylase 3 as a novel therapeutic target in multiple myeloma. Leukemia 28: 680-689, 2014

35. Jiang QG, Li TY, Liu DN and Zhang HT: PI3K/Akt pathway involving into apoptosis and invasion in human colon cancer cells LoVo. Mol Biol Rep 41: 3359-3367, 2014.

36. Akakura S, Huang C, Nelson PJ, Foster B and Gelman IH: Loss of the SSeCKS/Gravin/AKAP12 gene results in prostatic hyperplasia. Cancer Res 68: 5096-5103, 2008.

37. Bateman NW, Jaworski E, Ao W, Wang G, Litzi T, Dubil E, Marcus C, Conrads KA, Teng PN, Hood BL, et al: Elevated AKAP12 in paclitaxel-resistant serous ovarian cancer cells is prognostic and predictive of poor survival in patients. J Proteome Res 14: 1900-1910, 2015.

38. Hayashi M, Nomoto S, Kanda M, Okamura Y, Nishikawa Y, Yamada S, Fujii T, Sugimoto H, Takeda S and Kodera Y: Identification of the A kinase anchor protein 12 (AKAP12) gene as a candidate tumor suppressor of hepatocellular carcinoma. J Surg Oncol 105: 381-386, 2012

39. Suren D, Yildirim M, Alikanoglu AS, Kaya V, Yildiz M, Dilli UD and Sezer C: Lack of relation of AKAP12 with p53 and Bcl-2 in colorectal carcinoma. Asian Pac J Cancer Prev 15: 3415-3418, 2014.

40. Choi MC, Jong HS, Kim TY, Song SH, Lee DS, Lee JW, Kim TY, Kim NK and Bang YJ: AKAP12/Gravin is inactivated by epigenetic mechanism in human gastric carcinoma and shows growth suppressor activity. Oncogene 23: 7095-7103, 2004.

41. Burnworth B, Pippin J, Karna P, Akakura S, Krofft R, Zhang G, Hudkins K, Alpers CE, Smith K, Shankland SJ, et al: SSeCKS sequesters cyclin D1 in glomerular parietal epithelial cells and influences proliferative injury in the glomerulus. Lab Invest 92: 499-510, 2012.

42. Gelman IH: Suppression of tumor and metastasis progression through the scaffolding functions of SSeCKS/Gravin/AKAP12. Cancer Metastasis Rev 31: 493-500, 2012.

43. Radeva MY, Kugelmann D, Spindler V and Waschke J: PKA compartmentalization via AKAP220 and AKAP12 contributes to endothelial barrier regulation. PLoS One 9: e106733, 2014

44. Schott MB, Gonowolo F, Maliske B and Grove B: FRET biosensors reveal AKAP-mediated shaping of subcellular PKA activity and a novel mode of $\mathrm{Ca}(2+) / \mathrm{PKA}$ crosstalk. Cell Signal 28: 294-306, 2016.

45. Pilarsky C, Wenzig M, Specht T, Saeger HD and Grützmann R: Identification and validation of commonly overexpressed genes in solid tumors by comparison of microarray data. Neoplasia 6 : 744-750, 2004

46. Setia S, Nehru B and Sanyal SN: The PI3K/Akt pathway in colitis associated colon cancer and its chemoprevention with celecoxib, a Cox-2 selective inhibitor. Biomed Pharmacother 68: 721-727, 2014.

47. LaBonte MJ, Wilson PM, Fazzone W, Russell J, Louie SG, El-Khoueiry A, Lenz HJ and Ladner RD: The dual EGFR/HER2 inhibitor lapatinib synergistically enhances the antitumor activity of the histone deacetylase inhibitor panobinostat in colorectal cancer models. Cancer Res 71: 3635-3648, 2011.

48. Ye Y, Jin L, Wilmott JS, Hu WL, Yosufi B, Thorne RF, Liu T, Rizos H, Yan XG, Dong L, et al: PI(4,5)P2 5-phosphatase A regulates $\mathrm{PI} 3 \mathrm{~K} / \mathrm{Akt}$ signalling and has a tumour suppressive role in human melanoma. Nat Commun 4: 1508, 2013. 